\title{
Viajes, consumos y desigualdades. Notas para pensar la cuestión social urbana
}

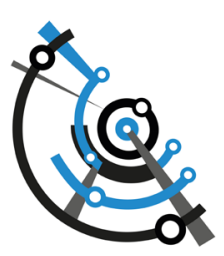

\section{(4) Daniela Soldano \\ Facultad de Ciencias Jurídicas y Sociales- Universidad Nacional del Litoral /Instituto del Conurbano- Universidad Nacional de General Sarmiento, Argentina}

Recibido: 31 de mayo de 2019. Aceptado: 4 de septiembre de 2019.

\begin{abstract}
Resumen
Este trabajo procura aportar a la comprensión de la riqueza de los viajes metropolitanos como fuente para la investigación sobre la cuestión social urbana en el Gran Buenos Aires, Argentina, entendiendo que los desplazamientos de los residentes de la periferia conectan a diario prácticas de reproducción y consumo fuertemente asociados a su capital espacial y marcadas por la desigualdad socio-económica. Para ello, se detiene en los consumos de rutina y ocasionales que se realizan "puertas adentro" del hogar así como en los que tienen lugar en los espacios colectivos que también funcionan como ámbitos de sociabilidad. En este punto, se detiene en la reconstrucción de las características y usos de una feria informal popular emplazada en el barrio. Se propondrá que en ambos registros no sólo vale la pena concentrarse en las mercancías que se consumen, en la determinación territorializada de su valor de cambio y en los usos sociales de los espacios dónde estas se ofrecen y se compran; sino que es especialmente relevante vincular todo esto a las capacidades materiales y simbólicas de desplazamiento de los actores sociales, en otras palabras: al capital espacial de los habitantes metropolitanos.
\end{abstract}

Palabras clave: Viajes. Consumo popular. Desigualdad social. Capital espacial. Periferias metropolitanas.

\section{Travel, consumption and inequalities. Notes on the urban social question}

\begin{abstract}
The purpose of this article is to call the attention to the fertility of metropolitan trips as a primary source to investigate the social urban question in the Great Buenos Aires area of Argentina. Daily commuting of peripheral residents connects reproduction and consumption practices, which are closely associated to their spatial capital and forged by socioeconomic inequality. To that end, the article focuses both on daily and occasional consumption made "indoor", within the household, and those taking place in public spaces which at the same time work sociability areas --analyzing specifically
\end{abstract}


the characteristics and uses of an informal fair that works in the neighborhood. This focus not only reveal the products traded and consumed, the territorial dimension or their exchange value, or the social uses of this informal market. It also tells much about the material and symbolic travelling capacities of social actors -in other words, about the "spatial capital" of metropolitan dwellers.

Keywords: Trips. Popular consumption. Social inequality. Spatial Capital. Metropolitan peripheries. Palavras-chave: Viajar. Consumo popular. Desigualdade social. Capital do espaço. Periferias metropolitanas.

\section{Introducción}

En la noche temprana de un día de semana, cualquier estación de tren del área metropolitana de Buenos Aires es un hervidero de desplazamientos acelerados, entre el andén del ferrocarril y las paradas de trasporte colectivo que llevarán a hombres y mujeres a sus casas, sitas en barrios periféricos. El frenético movimiento de cuerpos involucra a trabajadores que regresan luego de una larga jornada y que ya han logrado resolver una parte sustantiva de ese omnipresente plan cotidiano: gestionar los complejos viajes, con varias etapas y cambios de modo.

Pero antes de eso, y a pesar de estar verdaderamente extenuados, los viajeros metropolitanos procuran realizar algunas operaciones de mercado cruciales. Se mueven certeros a conseguir carne, verduras, productos de limpieza, librería y medicamentos en puestos informales o en locales cercanos a la estación. En los barrios, lo saben, no los conseguirán o costarán mucho más caro. También acarrean, en sus bolsos y carteras, objetos y alimentos que compraron en el tren o en la estación cabecera del ferrocarril del que acaban de bajar. Quizá hasta incluso apagaron un poco el hambre con alguna comida al paso.

Este trabajo procura aportar a la comprensión de la riqueza de los viajes metropolitanos como fuente para la investigación sobre la cuestión social urbana, entendiendo que los desplazamientos de los residentes de la periferia conectan a diario prácticas de reproducción y consumo fuertemente asociados a su capital espacial y marcadas por la desigualdad socio-económica.

Investigar empíricamente la desigualdad supone la difícil tarea de registrar e inscribir el trabajo rutinario de reproducción ampliada de la vida en una estructura de opciones dada, es decir, poner en relación analítica condiciones, prácticas e interpretaciones. En este punto, la sociología fenomenológica ofrece un recurso analítico crucial: la noción de experiencia, la cual permite resolver el divorcio entre el análisis de la estructura de la desigualdad y sus imaginarios (Schütz, 1970). A partir de esta perspectiva, es posible afirmar que la percepción de la desigualdad no es una operación recurrente de la vida social. Por el contrario, supone un proceso de construcción intencional de los actores, un razonamiento evaluativo sobre la propia situación, la de los otros (lejanos y cercanos) y sobre las diferencias, en relación a criterios más o menos procedimentales o normativos de justicia en torno a la asignación y distribución. Lo que resulta de esta contrastación - esta distancia o brecha- es tematizada de modos diversos. Algunas desigualdades se apreciarán como justas y otras como injustas (Soldano, 2019).

El campo del consumo es especialmente fértil para comprender estas experiencias. Este artículo pone el foco en éste -sus prácticas, objetos, modos y espacios-, proponiendo que el análisis de los consumos le permite al investigador ubicarse en un registro de la vida social donde los actores sociales resuelven a diario la reproducción de la vida, sorteando vivencias de frustración o disfrutando pequeñas conquistas materiales, todo lo cual forma parte central de su subjetividad y de la sociabilidad. Se planteará, así, 
que tanto en los consumos puertas adentro del hogar como en los realizados en los espacios comunes, vale la pena detenerse en las capacidades materiales y simbólicas de uso del espacio. En otras palabras: en el capital espacial de los actores y los niveles de relegación urbana que lo condiciona.

El recorrido comienza con breves señalamientos conceptuales que apuntalan esta conexión y continúa con un análisis de ambos espacios de consumo, a propósito de una investigación empírica realizada en varias etapas entre los años 2003 y 2014 en el partido de José Clemente Paz, situado a 35 kilómetros de la Ciudad Autónoma de Buenos Aires. Específicamente, el trabajo de campo se concentró en un área del borde del distrito -el del límite con el municipio de Pilar- que puede ser vista como una zona de interfase entre el tradicional suburbio y el nuevo periurbano. Por los altos niveles e intensidad de la pobreza - de las más altas de Conurbano Bonaerense- los tipos de inserción precaria e informal al mercado de empleo, la situación de escasa cobertura y baja calidad de los servicios sociales y urbanos y su distancia con la ciudad central de la que depende para dicha inserción y accesos críticos, la región analizada presenta un conjunto de características que permiten estilizar las condiciones y modos de vida de residentes de franjas metropolitanas periféricas. (Soldano, 2018; Soldano y Palma Arce, 2010)

La investigación en la que abrevan estas notas se realizó conforme a un diseño metodológico de corte cualitativo y etnográfico centrado en la producción de fuentes primarias en dicha área testigo (Duhau y Giglia, 2008) El mismo incluyó entrevistas en profundidad, observaciones, historias de vida e historias de casos de familias (Bertaux, 1996) realizadas a un conjunto de 25 grupos familiares elegidos en función de sus trayectorias laborales dominantes, la composición familiar y la experiencia de recepción de distintos programas sociales.

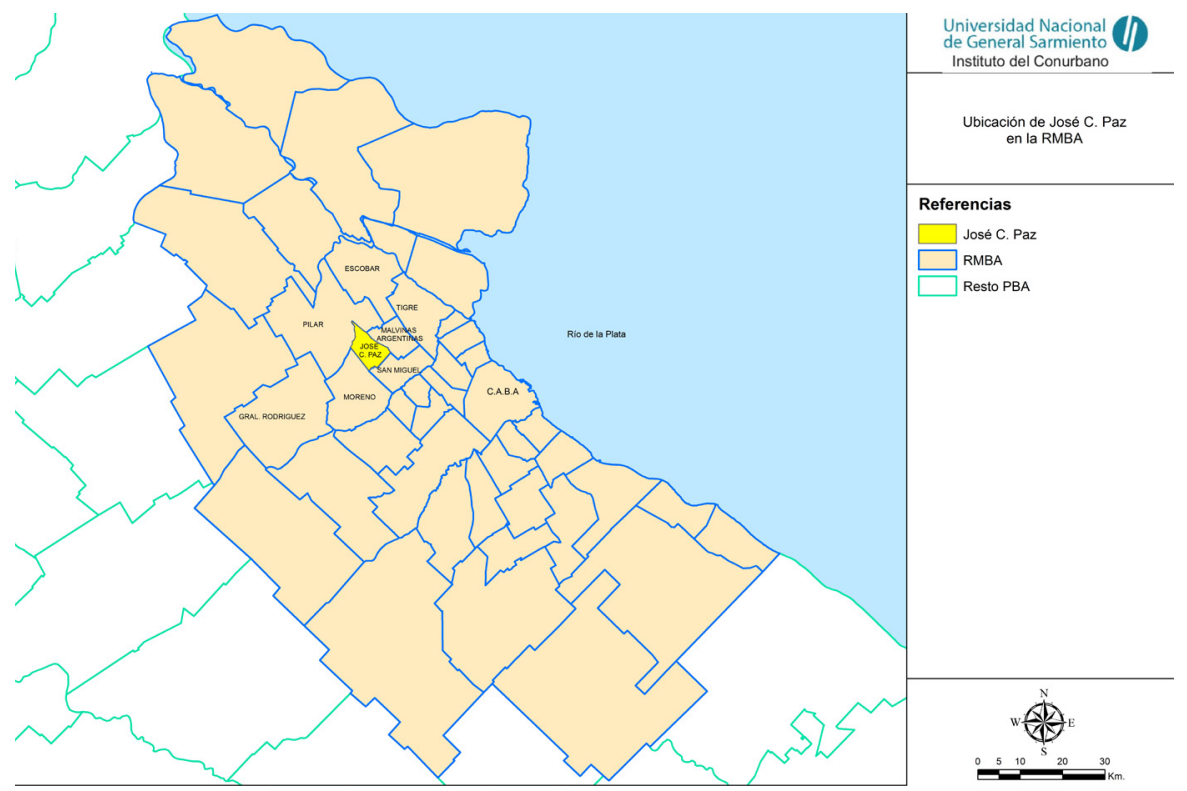

Figura 1. Ubicación del área testigo de la investigación. Fuente: Elaboración propia sobre la base de imagen satelital Google Earth e IDE Conurbano. Universidad Nacional de General Sarmiento (2016). 


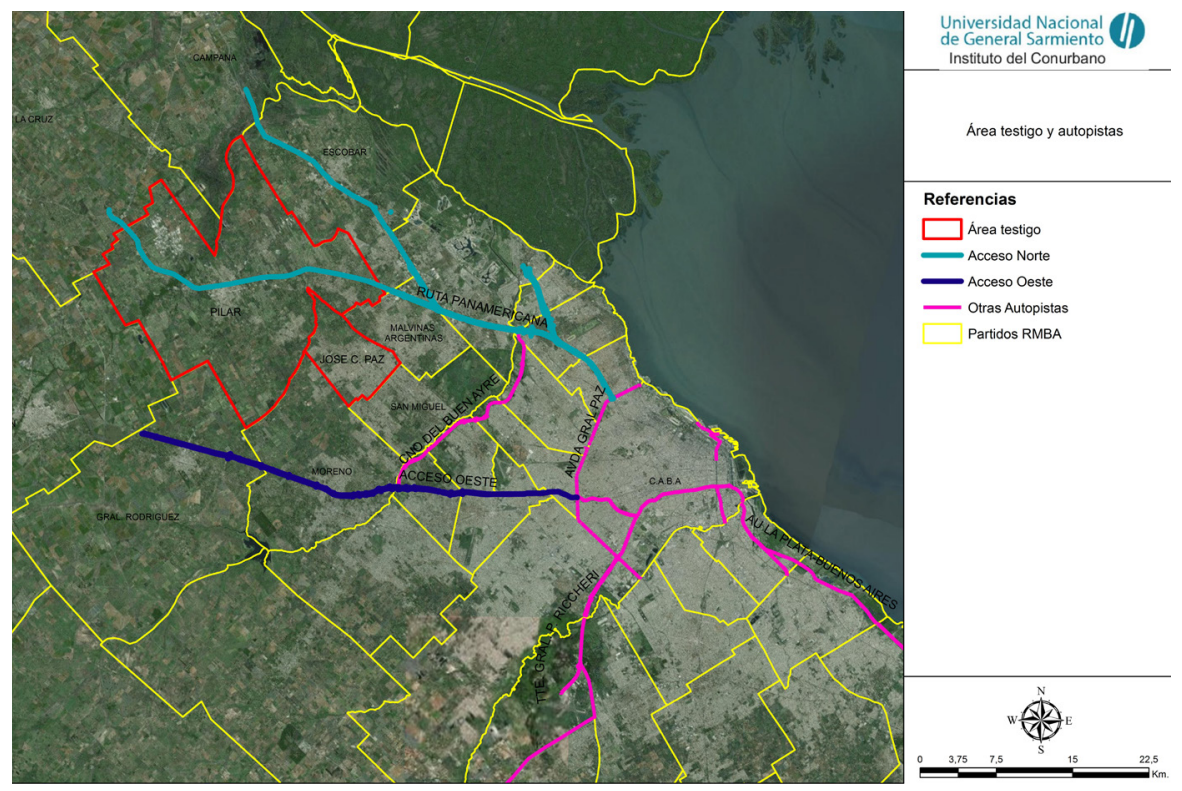

Figura 2. Ubicación del partido de José C. Paz en la Región Metropolitana de Buenos Aires. Fuente: Elaboración propia en base a IDE Conurbano. Universidad Nacional de General Sarmiento (2016)

\section{Alfajor y monedas. Dos notas de campo y una aproximación conceptual}

Corre el año 2009. Entre la miríada de puestos de venta de todo tipo montados sobre mesas precarias de la estación de José C. Paz del Ferrocarril San Martín un pregón se destaca del resto y grita: "alfajor y monedas". Es que se acaba de imponer la utilización de máquinas expendedoras de boletos en los colectivos y estos requieren el pago en monedas. Para los viajeros que toman seis medios de transporte a diario, los requerimientos de éstas son muy altos. De modo que se agolpan y forman fila frente a una suerte de mostradores hechos de cajones de madera que en el pasado han transportado frutas y verduras y que ahora hacen las veces de ventanilla bancaria para obtener el preciado bien: ocho monedas y dos alfajores a cambio de un billete de diez pesos. Una forma extraña de resolver la ausencia del metal que, si bien se reconoce como poco eficiente e incluso poco ética, a esa hora, con ese cansancio y con esa urgencia de llegar a casa, se presenta como la única opción posible y no se cuestiona.

Las ocho monedas están prensadas por una cinta adhesiva y se guardan como un tesoro en billeteras deformadas por su peso y en pequeños monederos - de todo tipo y colorcuyo uso se ha extendido exponencialmente. Los alfajores, por su parte, en general no se comen. Son de tan baja calidad que ni los perros de la estación los quieren. Se pueden ver tirados por allí, carentes de todo valor. La golosina condensa el impacto de una práctica usurera en contextos de relegación urbana en dos tapas y un relleno de gusto incierto. Son una suerte de medida de la desigualdad que somete a diario a los viajeros metropolitanos, y que en su consumo incorpora (o porta) una dosis importante de táctica y resignación.

Otra escena, esta vez de 2018, ${ }^{1}$ ocurre en un supermercado de la periferia del partido de Merlo, provincia de Buenos Aires, adonde se ha montado un patio de comidas junto a un pequeño parque de diversiones y unas salas de cine. La estética general es la de la típica área de esparcimiento de un shopping. En el patio de comidas se exhiben bandejas con milanesas, carnes horneadas y guisadas, papas fritas, pastas, ensaladas, tartas y 
empanadas. La exhibición es ostentosa porque su público no tiene, en general, dinero para comprarla. Cuando se aleja el personal de seguridad, algunas personas comen de éstas, rápida y furtivamente.

Más allá de alguna mirada sorprendida o despectiva, la escena no es especialmente repudiada ni denunciada. Los vecinos expectadores sotienen "la gente tienen hambre y ahí hay comida". El lugar en el que está emplazado el local con impronta global es grabado con las marcas de un territorio de pobreza extrema y relegación urbana. Los consumidores distan de ser los pretendidos por la empresa.

Además de hablar de las drásticas transformaciones de la estructura social argentina en el cambio de siglo y en las dos décadas que ya transcurrieron, estas pinceladas empíricas sirven como disparador para analizar la conexión profunda que existe entre los viajes, la desigualdad y las experiencias de consumo. En efecto, éstas no solamente se vinculan, como postula la sociología clásica de Simmel (1977) y Bourdieu (1998) al capital económico y cultural de los agentes sino a sus condiciones espaciales de vida: a su capital espacial. Con este concepto se incluye tanto las posibilidades que brinda la posición, es decir, la localización de las viviendas en relación a la oferta de transporte, accesibilidad y conectividad como la situación de las personas en relación a los recursos para la movilidad; tiempo, dinero, y expectativas. (Levy, 2003; Marcus, 2010; Fournier, 2008; Palma Arce, 2012; Palma Arce y Soldano, 2010; Apeazola et al., 2016)

Merece la pena, entonces, plantear la siguiente hipótesis. La periferia del área metropolitana muestra la presencia de circuitos de consumo restringidos y subordinados, en cuanto al tipo, calidad y condiciones de acceso y circulación de las mercancías, circuitos que moldean una suerte de infra-consumidores. Uno de los indicadores de este proceso es el valor de cambio territorializado de los objetos y productos que se comercializan. En efecto, tanto la compra y venta de monedas (y el descarte de los alfajores) como la de los alimentos que se arrebatan de las bandejas, se rigen por reglas espacialmente situadas que serían cuestionadas fuera de estos lugares. Otro indicador es el hecho de que aunque se emplacen solares que emulen las prácticas de consumo de los sectores medios -como anticipaba Sarlo (2009)- en ellos suceden prácticas localizadas que desafían sus fines y estéticas.

Ahora bien, si el estatus social es definido por la capacidad de consumir y su ampliación, se considera parte importante de procesos democratizadores, entonces seguramente cualquier aumento en este campo supone mayores niveles de integración social. Esto es, en efecto, lo que suponen ciertos modelos hegemónicos de política social en la región, que se basaron en la implementación de transferencias monetarias a los sectores vulnerables con el objeto de asegurar ciertos niveles de consumo. Un ejemplo de estas perspectivas puede leerse en el trabajo elaborado por Guedes y Oliveira (2006) sobre el consumo de sectores populares en la periferia de San Pablo. En éste, junto con el reconocimiento de la amenaza de créditos de carácter leonino que imposibilitan un crecimiento económico sustentable, se propone la idea de que la entrada al consumo de bienes durables por parte de amplios sectores de la población, más allá de la heterogeneidad de actores que se desempeñan en el mercado informal, puede pensarse como un proceso que contraviene a la desigualdad. ${ }^{2}$

Aquí se sostiene que aunque puede ser cierto que el auge de los créditos al consumidor pueda funcionar como importante igualador social mediante el acceso a televisores, lavarropas, o celulares, esos consumos, lejos de demostrar el desarrollo de performances 
cada vez más vinculadas a las de las clases medias (lo que el sentido común considera como punto de consumación de la ciudadanía social), poseen una gramática propia fuertemente territorializada. En lo que sigue, se propondrá una lectura posible de estos fenómenos.

\section{Consumos de rutina y puertas adentro en contextos de relegación urbana}

En la vida cotidiana de los habitantes de la periferia urbana el consumo se efectúa muy habitualmente en relación directa con los viajes al trabajo. En efecto, el vecino que sale del barrio es, además, el que se encarga de las compras en las inmediaciones de la estación ferroviaria u otros nudos céntricos por los que haya pasado a lo largo día. Mientras tanto, el que se queda y no se traslada más que a pie, es el que espera el dinero ganado a diario por el que viajó. Esta interacción de rutina altera y acelera el paisaje de los barrios populares cuando cae la tarde y a la noche, desde las casas y hacia el pequeño mercado o almacén.

Para cualquier investigador de la cuestión social urbana en el Gran Buenos Aires, un momento especial para advertir dicha condición ha sido la crisis de 2001-2002. En efecto, debido a la drástica reducción de la oferta de puestos de trabajo en la construcción y el servicio doméstico, en este lapso se profundizó el repliegue de estos grupos sociales en los barrios generando una suerte de insularización extrema de sus condiciones y modos de vida. (Cravino et al., 2002; Soldano, 2008)

$\mathrm{Si}$, como plantea Aguirre (2005), las canastas alimentarias de los barrios pobres en áreas urbanas se encuentran estructuralmente marcadas por la relegación y las distancias, es en años como esos donde la condición espacial de la reproducción de la vida queda exponencialmente expuesta.

La falta de ingresos monetarios hace que los esfuerzos cotidianos se concentren en la elaboración de un plato de comida para la cena. Los niños almuerzan en los comedores escolares y los adultos saltean la ingesta con mate dulce y pan o la resuelven con una comida al paso provista por el mercado informal, una alternativa de abastecimiento rápido y barato. En efecto, los individuos en tránsito recurren a los puestos de tortilla, panchos, chorizos y hamburguesas, los que a su vez suelen ser refugio ocupacional de esta misma población.

Asimismo, en las canastas de los hogares de sectores populares se conjugan las comúnmente denominadas por los residentes "mercaderías" (fideos, arroz, azúcar, aceite y yerba), con la leche, el pan, algo de verdura (papa, cebolla, zanahoria, en menor medida verdura de hoja y frutas) y cortes baratos de carne. Consumir algún corte de carne, verdura de hoja, fruta, yogur o queso es percibido como una suerte de consumo de lujo o extraordinario, resuelto en general por el que sale del barrio a trabajar, a estudiar o a conseguir alguna prestación médica. Así, la vida cotidiana muestra una dinámica de consumo hormiga, del día a día, de pequeños movimientos, sin posibilidades de acumulación y escasa capacidad de previsión. Si no hay dinero, no sale nadie y no se mueve nadie. Si no hay dinero, la comida no llevará carne o no habrá frutas para la cena. La gestión del plato de comida, en este sentido, es incremental y minimalista y se vincula a las metas y resultados efectivos de la movilidad cotidiana.

Como se lee en las entrevistas realizadas a tres vecinas residentes de la zona analizada, esta gestión actualiza a diario la percepción de los contrastes entre lo deseado, lo considerado "bueno" y lo obtenido. Es decir, actualiza a diario la experiencia de la desigualdad. 
¿Dónde realizás tus compras habitualmente?

En el mercado del barrio, en el almacén del barrio, todo en el barrio.

¿Hacés alguna por semana o por mes?

No, no las podemos hacer. Solo por el día.

¿Y qué es lo que comprás por día?

Depende lo que se va a comer en el día. Y lo que vas haciendo diariamente. Al mediodía se cocinó lo que se cocinó y lo que quedó a la noche se agrega algo y se come lo que quedó del mediodía. (Entrevista a vecina. Julio de 2004)

¿Cómo son tus compras? ¿Cómo te organizás?

Compro lo justo y lo necesario para el día, para la comida. Yo vivo al día. Yo no soy una persona muy ambiciosa. A mí me gustaría comprar lo que haga falta para terminar mi casa. Estar cómodos. (Entrevista a vecina 2. Julio de 2004)

¿Cómo son tus compras? ¿Dónde compras?

Compro todo acá en el barrio, en el mercadito de acá que es el más barato de acá. Cuando tengo les compro alguna cosita. Ayer el padre le trajo zapatillas. No podemos sacar créditos porque no tengo ningún plan y no pagamos la luz nada. Viste, acá nadie paga la luz porque está el medidor allá así que ninguno paga la luz. Y para el agua ahí, tengo una bombita, tengo una centrífuga sin medidor. No te queda otra. Te dan ganas de comprar milanesas o comer más pollo, pero no podés porque después te quedás en cero. Tenés que regular y es como que ya aprendés a vivir con esa angustia. (Entrevista a vecina 3. Septiembre de 2004)

Los des0plazamientos en general -y los de las compras en particular- se encuentran severamente acotados y de ellos dependen las variaciones del plato que logre elaborarse. Buscar precios, cazar ofertas, comprar aprovechando el viaje de algún miembro del hogar, hacer alguna pequeña reserva de lo no perecedero, forma parte de las tácticas cotidianas de los vecinos para "hacer rendir la plata". A veces, como en el tercer testimonio, se sabe lo que se quiere pero no se puede.

Si bien el grueso de las familias sigue este ritmo, un conjunto minoritario puede realizar compras con cierto nivel de planificación semanal, quincenal o incluso mensual, debido a que algunos de los adultos recibe algún pago (de salario o de algún plan social) con esa regularidad. En esos hogares, se destina dinero para pago de la energía eléctrica y, si se puede, para la generación de algún stock de mercadería. Puede apreciase, así, una relación de ampliación de los repertorios de consumo conforme aumenta la "profundidad temporal del ingreso" (Aguirre, 2005). Entre los productos fundamentales, de consumo más lento y que exigen una búsqueda de mejores precios, se destacan el aceite y los de perfumería y limpieza.

La gestión minimalista de la rutina alimentaria se basa en la elección de cortes de carne baratos, la renuncia a la calidad en función del precio, la postergación de los alimentos de lujo tales como el asado, la fruta y el yogurt y la centralidad de los alimentos secos como los fideos y el arroz en torno a los cuales pivotea la dieta cotidiana posible. En el relato siguiente aparecen con nitidez razonamientos vinculados a las distintas dimensiones del consumo. 
¿Y ustedes dónde compran la mercadería y las cosas de la comida, por ejemplo?

Bueno, nosotros por lo general compramos diariamente la comida. No hacemos pedidos como antes

¿Antes sí hacía una compra semanal o mensual?

Mensual porque verdaderamente, teníamos un sueldo, había un sueldo de por medio y entonces iba y compraba todos los elementos básicos que se usaban dentro de lo que es la canasta familiar y después bueno, diariamente el pan, la carnes, ésas cosas se compran en el barrio. Ahora no. Muy pocas veces vamos al centro... (Entrevista a vecino 4. Agosto de 2004)

Algunos trabajos sobre los impactos de la política alimentaria y asistencial en las biografías y espacios sociales de relegación urbana han confirmado ya estas relaciones. ${ }^{3}$ Sin embargo no ha sido trabajada la relación del consumo con la relegación urbana y la desigualdad, lo que aquí se denominará el carácter espacial de las mercaderías.

En efecto, durante más de dos décadas, y por el hecho de habitar en este tipo de barrios con altos niveles de necesidades básicas insatisfechas, la mayoría de las familias recibió de modo sistemático una serie de comestibles que constituyeron una suerte de línea de base en la elaboración del plato de comida diario -fideos secos, avena, yerba, harina y avena- con fuerte impacto en la comensalidad familiar ${ }^{4}$. Las instituciones no permanecieron ajenas a estos procesos. Durante estos años y hasta la actualidad, los comedores escolares y comunitarios reiteraron además de la copa de leche, las recetas de la comida colectiva y rendidora, saturada de pastas y grasas.

Un caso testigo del impacto de las mercaderías que "bajaban" de los planes sociales en el paisaje de los barrios fue durante muchos años la avena. En las investigaciones realizadas a fines de la década de 1990 ya se señalaba la sobreabundancia de este cereal y la escasez de alimentos centrales para dar un salto cualitativo en el plato, tales como el aceite de calidad, los huevos, la carne y las verduras. Era común en esa época escuchar los fundamentos nutricionales del discurso oficial y el conflicto que generaba con las representaciones de las mujeres sobre lo que se consideraba una buena comida. La tensión del plato rendidor, de la comida guisada, que se cocina en una olla y que no requiere necesariamente de una mesa y de cuchillo y tenedor.

En este punto, el análisis del comensalismo que realiza Tilly (2000) es iluminador de la estructura de la desigualdad y de las relaciones sociales organizadas por categorías que atraviesan la sociabilidad cotidiana y que la política social reproduce.

El comensalismo relaciona a las personas, pero también depende de relaciones fuertemente estructuradas entre ellas (padre/hijo, mujer/marido) en las cuales entran en juego criterios de adecuación "nutricional" o similar (...) Lo que la comida decía sobre la relación entre el donante y el receptor. (2000: 59/60)

Asimismo, el enfoque de la antropología alimentaria permite analizar los componentes reproductivos del consumo en clave de la relación entre capital económico y capital

3 Véase Colabella (2015).

4 En el plato de comida de los sectores populares urbanos predominan las formas de cocción guisada y sopas las que permiten la mezcla y cocción sencilla y aumentan el volumen y el poder de saciedad del plato. (Aguirre, 2005) Por otra parte, permite una gestión de la mesa más sencilla que requiere menos espacio y menos vajilla y menos consumo energético de gas en garrafa. 
cultural de los sujetos, donde tiende a darse una relación funcional entre la posición objetiva y la disposición adquirida y a modelarse no sólo el cuerpo sino cierto estilo de vida. En éste, los gustos de necesidad aparecen como elegidos, protegiendo del deseo y la frustración y siendo refractario a la búsqueda de alternativas.

No obstante, hay una condición espacial de los productos que modela las canastas, las recetas y la subjetividad. Mientras la publicidad bombardea con alimentos modelo, que harán crecer a los niños fuertes, inteligentes y sanos (como las de Danonino o yogurísimo) y en el centro de salud el pediatra les pide a las madres que procuren dietas variadas, las mujeres gestionan recetas reiteradas y empobrecidas y pagan con su tiempo y su cuerpo la sustitución alimentaria por dos vías: al elaborar en forma casera lo que antes compraban (por ejemplo, amasando) y comiendo menos.

\section{Los consumos ocasionales, entre las segundas marcas y el crédito fácil}

En el consumo de artículos tales como celulares, zapatillas, ropa, electrodomésticos y artículos electrónicos se despliegan otro conjunto de temas relevantes: el circuito de artículos de baja calidad ("truchos") y el acceso al crédito fácil y caro por parte de los habitantes en condición de pobreza, relegación urbana y alta vulnerabilidad laboral. Ambas cuestiones, como queda de manifiesto de manera regular en el estudio realizado, condicionan las experiencias cotidianas de los vecinos, ya que por un lado satisfacen la necesidad en el corto plazo y por otro, perpetúan la heteronomía.

¿Y dónde comprás la mercadería y las cosas para comer?

Acá, en el barrio. En el mercado del barrio, porque más barato que acá no lo encuentro. Algunas cosas por ahí voy al COTO, aceite... pero generalmente acá, en el barrio

¿Y zapatillas y ropa para vos y los chicos?

No, mirá... no... sí, le compro. Tienen de a dos pares, tres, tienen

¿Pero dónde comprás? ¿Por crédito?

No, de marca no les compro. De marca no les compro. Nosotros tampoco usamos ropa de marca. Compramos al contado. Por ejemplo, una quincena uno, otra quincena otro y así. $\mathrm{O}$ a los chicos cuando cobra salario, como cobra salario en blanco, cuando cobra salario generalmente vas y comprás calzado

(Entrevista a vecina 5. Enero de 2006)

La baja calidad de los productos, en este caso un par de zapatillas que los chicos llevarán puestas todos los días, redundará en que estas se rompan, se descosan y se despeguen en poco tiempo. La vecina sabe que si pagara más accedería a algo mejor y que comprar zapatillas "truchas" provocará que tenga el problema instalado, de nuevo, en poco tiempo. Sin embargo, una vez más, esta es su opción.

En el mismo sentido, los viajes suelen permitir a los vecinos resolver consumos no fundamentales, por ejemplo el de los regalos y juguetes que saben, se romperán enseguida. Lo barato es lo accesible, pero es de corto plazo. 
Mirá la montaña de chucherías que compro en el tren, muñequitos sin cabeza, marcadores que no andan, todas porquerías que sabés que no tenés que comprar. (Entrevista a vecina 3. Enero de 2006)

Buena parte de las familias del barrio toma créditos "a sola firma" para comprar artículos en las principales cadenas de venta de productos para el hogar (v.g Garbarino y Las Malvinas) y en las casas de deporte del centro de José C. Paz. En estos locales, practicamente cualquiera puede acceder a una Prestacash, Credipaz, Provercred, Credi-al, Ital-cred, Cash-ahora y Lider-cred, sistemas que financian hasta 30 cuotas, en el acto, sin informe comercial (veraz) y hasta los 86 años de edad. Si bien el acceso es fácil, vía la presentación de un documento que acredite la identidad y recibo de cobro de algún plan social o pago de servicio, los intereses son elevadísimos. En general los vecinos reciben bonos y chequeras ya que el interés por retirar dinero en efectivo es muy oneroso. El mantenimiento de la tarjeta, por el contrario, es muy barato.

¿Y ropa y zapatillas dónde comprás para los chicos?

Y, ropa yzapatillas siempre estoy comprando con prestacash. Te la dan por tener un plan. Casi que te la regalan. Estoy por terminar de pagar las zapatillas que le saqué hace poquito acá en Sport, Ahí compré para los dos chicos. Estoy terminando de pagar y ya se les están arruinando todas las zapatillas. Y a las nenas siempre alguien les está regalando. Así que mi nena se anda quejando "mamá, comprame esto". Ah, el otro día les compré acá en la tienda Los Hermanos también. Las zapatillas, unas comuncitas, ahí están baratas. Pero siempre trato, cuando veo que ya las zapatillitas no dan más les compro. (Entrevista a vecina 4. Marzo de 2005)

¿Y dónde vos realizás tus compras habitualmente?

En Los Hermanos. Lo que uso muchísimo -a veces nos reímos de contarloprestacash. El famoso prestacash, que es el que me consume, en un sentido, de que todo lo que cobro, tengo que ir a pagar ahí.

Claro. Cobrás y pagás.

Pero siempre compro alimentos. Sí. Cuando no tengo nada, uso mi prestacash. (Entrevista a vecina 3. Marzo de 2005)

"La prestacash me consume", señala la vecina y en su relato se estiliza este círculo vicioso que se genera entre la cadena de endeudamiento de alto costo y las necesidades de consumo que se reinstalan -una y otra vez- por la baja calidad de los productos obtenidos.

Entre los consumos ocasionales, más allá de la ropa, el calzado y los celulares y artículos electrónicos, se distinguen algunos asociados al ocio y al esparcimiento también regulados por la restricción espacial. Los jóvenes, por ejemplo, se juntan en las casas, en las esquinas -fundamentalmente si hay algún kiosco cerca- y suelen desplazarse a las bailantas y boliches de José C. Paz, si es que consiguen entradas gratis o eventualmente cuentan con el dinero.

Entre los adultos, las prácticas de tiempo libre se desarrollan en las casas y en la feria cartonera, a la que se hará referencia en el próximo apartado. Algunos hombres juegan al fútbol con amigos en la canchitas improvisadas, mientras los hijos y las mujeres miran televisión o toman mate. La visita a familiares en barrio contiguos aparece como el principal fin de desplazamiento en el tiempo libre, porque tiene bajo o nulo costo.

Otro elemento de goce o gratificación está presente en los "alimentos regalo" (Aguirre, 2005) y las salidas. Entre los primeros, claramente se destacan la carne asada, el vino y 
las milanesas con puré, platos que se definieron en las entrevistas como comidas que gratificantes y que invitan a la reunión familiar. Además de éstas, se mencionan las actividades de esparcimiento que implican desplazamientos desde el barrio y ciertas erogaciones razonables de dinero. Entre los posibles programas de esparcimiento para los niños se encuentran los juegos de los McDonalds de algunos supermercados y la salida al parque zoológico de la ciudad de Buenos Aires, al que se accede tomando el tren San Martín. Sin embargo, debido a los altos costos de ambos programas el esparcimiento se resuelve en el espacio de proximidad, todo lo cual habilita, a hablar de formas de ocio fuertemente insularizadas (Soldano, 2008).

En efecto, salir del barrio tiene un costo demasiado elevado, no solo objetivo, vinculado al precio de los traslados, al riesgo de dejar la casa sola por si alguien entre a robar; sino también subjetivo. Muchas mujeres se refirieron a la ardua gestión de la negativa a los pedidos de los hijos y a su consecuente frustración y dolor al tener que decir "todo el tiempo que no". Si salir es exponerse al mercado, quedarse en el barrio es mantenerse cerca de lo posible, que es lo que está en el espacio de proximidad.

Y son tantas cosas... porque una de ellas son también ropa, calzado para los chicos. En un sentido que por ahí le buscás la forma de comprar la zapatilla más barata pero cuánto le dura. No le dura casi nada. (...) Por ahí son tonteras para los demás pero para los chicos, para mí como mamá que no le puedo alcanzar, o me dice "mamá, comprame esto". Y no está por ahí a mi alcance de comprárselo. Por ahí, como mamá, las cuido un poco más para que ellas no se sientan mal tampoco. Pero duele, más si los chicos te piden y vos ves que no podés comprárselo. Son tantas cosas que te tengo que nombrar... (Entrevista a vecina 1. Abril de 2006. Enfasis agregado)

La televisión está siempre prendida en las casas, para ver la programación de aire o cable o para pasar películas pirata compradas en la feria o puestos callejeros. En efecto, la totalidad de los entrevistados ha dicho que la forma fundamental de entretenimiento del hogar es mirar televisión, cuestión que pude comprobar en el transcurso del trabajo de campo, en el que buena parte de las entrevistas grabadas tienen su rumor de fondo. Cuando pudieron, algunas familias hicieron el esfuerzo de pagar la televisión satelital. De hecho, pueden verse un número considerable de antenas Direct $T V$ en desuso que atestiguan esa aspiración y su efímera vida.

\section{Solares de consumo periferico}

Las familias que residen en el territorio bajo estudio suelen ir los fines de semana a la feria cartonera, un mercado popular e informal ubicado a cien metros de la estación ferroviaria en el que se comercializan ropa y artículos recolectados en los itinerarios de los cartoneros por los barrios de clase media. El solar constituye un espacio fundamental en la vida cotidiana de esta periferia ya que en ésta no sólo encuentran una forma posible de obtención de ingreso muchos de los vecinos sino que se despliega una activa sociabilidad de tiempo libre. La feria convive con espacios de comercialización formales, como el mercado concentrador ${ }^{5}$ y la zona de la estación de José C. Paz, nudo de las prácticas de viaje de los habitantes metropolitanos (Soldano y Da Representacao, 2010; Da Representacao, 2018).

5 El mercado concentrador fue inaugurado por el intendente Mario Ishii y el presidente Nestor Kirchner en 2007. Suele usarse, desde entonces, como un espacio para le realización de actos políticos del Partido Justicialista de la provincia y de la Nación. Se trata de un predio de grandes proporciones en el que se emplazan dos edificios, uno destinado a la venta de frutas, verduras, carnes y mercadería y otro, organizado como un paseo de compras, donde se realiza la venta de electrodomésticos, celulares, motos, CDs y DVDs, ropa, juguetes y servicios de esparcimiento. 
Los espacios de consumo, en tanto escenarios donde se despliega un universo cultural popular con una moralidad y reglas de intercambio propias, tienen un amplio arraigo en las ciencias sociales y los estudios culturales (Hoggart, 1990; Thompson, 2000; Grignon y Passeron, 1991; Alabarces y Rodríguez, 2008). En su trabajo pionero sobre los mercados populares, Jesús Martín-Barbero (1987) contraponía dos lógicas en la producción de valor y de intercambio: una lógica de la equivalencia, donde cada objeto tiene un valor abstracto que puede ser intercambiado por cualquier otro, propia de las mercancías capitalistas, y otra en la cual los objetos valen de acuerdo a quién los intercambia, más propia de los mercados y las moralidades populares. Una lógica de la abstracción, entonces, frente a una lógica de la ambivalencia y el deseo.

Pero además, la feria, junto con el centro comercial de la estación y el mercado concentrador, son cabales espacio comunes en el sentido que la literatura le confiere a estas arenas públicas de sociabilidad. En efecto, se trata de solares que permiten la co-presencia y convergencia de actores sociales -más o menos diversos- fuera de su marco doméstico, habilitando intercambios y relacionándose con objetos y formas espaciales (Lussault, 2003; Crosta 2000 citados en Da Representacao, 2018). Se trata, en suma, de espacios sociales heterogéneos en donde cobra relieve con especial nitidez el capital espacial de aquellos que participan.

Desde los tiempos de la crisis del 2001-2002, todos los sábados y domingos un conjunto de vecinos levanta en este predio un mercado en el que se ofrece mercadería recuperada del circuito del cartoneo. Desde esos días hasta el presente, entre la mañana y hasta aproximadamente las seis de la tarde, en el potrero donde los alumnos de una escuela primaria hacen los ejercicios de educación física durante la semana, se montan entre 500 y 600 puestos de venta de cosas de todo tipo. A diferencia de una feria como la de La Salada, donde se destaca la diversidad de los artículos a estrenar que están a la venta, la espectacularidad y la complejidad de niveles de poder o de una feria híbrida como la de Solano, donde lo informal manufacturado se prolonga en una red interminable de mantas que ofrecen desde máquinas de escribir hasta avestruces, el $90 \%$ de las mercaderías en la Cartonera son usadas y no existen jerarquías definidas. ${ }^{6}$

La razón fundamental de permanencia y crecimiento de la feria parece ser la gratuidad en el acceso al predio, tanto para los compradores como para los feriantes. A diferencia de otras ferias populares, además, en ésta no parecen existir lógicas de acaparamiento de oportunidades ni dirigentes que cobren peajes. Cualquiera puede ir con su manta o alquilar un puesto siempre que no obstaculice el acceso a otro puesto o manta ya instalado con antelación o que sea más antiguo en la feria.

Un núcleo duro de puestos ofrece mercadería bajada del tren, otros son montados por vecinos que ofrecen a la venta ropa nueva y artículos que han comprado especialmente para la reventa. Mientras que algunos puestos tienen techo y estructura, otros se disponen sobre mantas en el piso de tierra. En un puesto se venden licuados y se vende también la licuadora que los prepara; en otros se exhiben ollas, canillas, viejas revistas Caras y Gente, caños, tapas de luz, prendas de cualquier tipo y tamaño, alimentos, herramientas usadas, carpintería de aluminio, bobinas, zapatos de suelas planas, fotos enmarcadas de desconocidos, gorras de trabajadores de McDonald's, heladeras, veladores estilo Tiffany, un pistón de Falcon modelo 74 o polvorientos tomos de enciclopedias

6 Las ferias de la crisis y post-crisis han desaparecido lentamente de la CABA. Han sido reubicadas e intervenidas por el gobierno. En el AMBA hay ferias pero ninguna tiene los años de la crisis y ninguna se emplaza en la periferia. El análisis de ferias como La Salada está generalmente centrado en la escala, diversidad, ilegalidad y espectacularidad. En otras ferias, se han realizado análisis de las trayectorias laborales de los feriantes (tipologías de precariedad, vulnerabilidad, etc.) El análisis de la feria de San Francisco Solano -sobre todo el de los feriantes periféricos- es significativo en este sentido. Véase Chávez Molina, Comas y Alonso (2006) y Gago (XXX) 
Salvat, souvenirs de las "cajitas feliz" y los huevos Kinder y merchandising gastado y añejo que se vende por monedas, aunque es raro que alguien compre. Las funciones de la feria son múltiples: espacio de paseo, centro de abastecimiento y, fundamentalmente, plataforma de exposición de aquello que se recolecta.

Compradores y vendedores son en general vecinos que no pueden salir del barrio porque no tienen dinero para procurar el desplazamiento de toda la familia hacia sitios de provisión y esparcimiento. De hecho, la gran mayoría de los que no llegan caminando lo hacen en bicicleta. La proliferación de "guardabicis" anunciados con carteles manuscritos que afloran en cada jardín, en cada puesto o incluso en cada árbol, da cuenta de esto. Aun así, vecinos y puesteros repiten que "viene gente de todos lados", y hasta se habla de camionetas $4 \mathrm{x} 4$ que llegarían de otros municipios. Un mercado de esta clase permite consumir a un precio razonable y desarrollar formas de ocio puertas afuera del hogar. Puestos de comida donde se vende tortilla, milanesas, chorizos a la pomarola, permiten a hombres y muchas mujeres salir de sus casas y hablar con otra gente. Algunos domingos, bajo el sol y sobre el polvo de la plaza, se levanta un globo inflable donde por muy poca plata los chicos paceños pueden saltar, hacer piruetas y pasar la tarde.

Nuevamente el fenómeno de la feria cartonera puede pensarse en el marco de un proceso de cierta democratización del consumo popular o en términos de la consolidación de lógicas de confinamiento y desigualdad y segmentación de consumidores periféricos. Esta segunda perspectiva se apoya tanto en la existencia de repertorios de movilidad restringidos como en las formas territorializadas de determinación del valor de las mercancías. Las cosas que se venden tienen valor ahí donde se venden y a partir del reconocimiento que de éste realicen los consumidores insularizados.

Cobra sentido en este punto, el ensayo de Appadurai (1991) sobre la determinación del valor de las mercancías. Revisando la tesis de Simmel (1978) según el cual el motor del valor es el intercambio y la subjetividad que se inscribe en los vínculos fundamentalmente a través de deseo de consumo- Appadurai propone reposar la mirada en las cosas y sus biografías.

El valor está contenido en las mercancías que se intercambian, centrándose en las cosas que se intercambian, y no simplemente en las formas o funciones del intercambio (...) Es posible argüir que lo que crea la conexión entre intercambio y valor es la política, entendida en sentido amplio (1991:17).

La política, entendida en sentido amplio, se teje de modo invisible en la vida cotidiana, a través de las leyes de la moda, el tabú y la ley suntuaria que moldean culturalmente la demanda. La política es la matriz de relaciones, luchas de poder y formas de control social de la gente común por parte de las elites que produce el régimen de valor de las cosas. ${ }^{7}$ El precio de los artículos que se exhiben se determina por su tipo y en relación al valor de mercado. Por ejemplo, si es ropa nueva su valor será parecido o igual al de un comercio en el centro de José C. Paz o en la Feria de la Salada o en el mercado concentrador. En cambio, si es usada, el valor será el resultado de un cálculo basado en el dinero puesto en su restauración o reacondicionamiento, su carácter de satisfactor de alguna necesidad concreta o de si tiene utilidad.

7 Otros economistas que se inscriben en la tradición utilitaria o pragmática, sostienen que el proceso de mercantilización de los objetos responde a una lógica psicosocial, basada en el sentido social de lo utilitario. Es decir, que la valoración mercantil es simbólica y la cualidad esencial de los objetos es la utilidad. Siguiendo a Mead (1932), se puede afirmar que la resultante del acto social es, justamente una creación simbólica. El mundo simbólico que compartimos y que nos torna seres sociales objetiva y se objetiva en nosotros a través de un proceso comunicativo. 
Que la economía se rija por la localización de los productos no es una novedad, pero sí lo es que en la cotización de ciertos objetos-fetiche se dibuje otra relación entre precio, gratificación simbólica y mercado. Un ejemplo de esto puede advertirse en las mantas ubicadas sobre la tierra de la calle lateral a la plaza donde se venden bolsas vacías de marcas reconocidas. En efecto, marcas como Akiabara, Kosiuko, Complot, AY Not Dead, Bensimon o cualquiera que pueda revestir algún tipo de aspiracionalidad se exponen como puro signo, puro emblema de distinción, como continentes sin contenido. $\mathrm{Y}$ se trafican. Otro ejemplo, son los souvenirs viejos que servirían por su valor estético. Todos valen monedas: un secador de pelo de muñeca roto, los juguetes de la caja feliz de Mc Donald's, objetos de bazar usados.

El valor de las marcas, los millonarios presupuestos invertidos en publicidad y exhibición generan una extraña plusvalía en circuitos de consumo insularizados. En este punto, y contra lo que podría pensar la sociología más miserabilista, no hay consumo de necesidad ni simple reemplazo, sino otra cosa. Una suerte de experiencia de ostentación diluida, una muestra paga de la "experiencia" que, cada vez más, intentan vender esas marcas. Y no son las grandes firmas internacionales que se copian en talleres clandestinos, sino los sobrantes de las compras de las marcas de semi-diseño en la clase media ${ }^{8}$.

Por último, la feria es un espacio tan construido como en construcción, en la tensión que ejercen las miradas amables y las desconfiadas. Entre éstas últimas se destacan las de aquellos que piensan que no es legítimo vender lo que se junta y obtiene sin pagar, quienes cuestionan cómo se definen los precios y quienes impugnan la exhibición de la marginalidad que se reproduce en el espectáculo de la feria. En estas intervenciones se ponen en juego representaciones fuertes sobre ciertas personas y sus prácticas -los cartoneros- $y$ sobre los espacios que éstos construyen. La feria es vista como una cantera de marginalidad.

En suma, la feria cartonera es más que el nudo final del corredor que traza el tren y su parador. Para los habitantes de la periferia metropolitana es una parte del barrio, una ámbito de sociabilidad, de recreo, de encuentro; un sitio donde se hace concreto el consumo de lo posible y de intercambian imágenes sobre lo deseado.

\section{Conclusiones}

Se ha argumentado en este trabajo que el capital espacial debe ser integrado a la hora de pensar la cuestión social y la movilidad en la periferia urbana. Los consumos llevan implícita una fuerte marca que se vincula con las distancias y el confinamiento territorial de los residentes. Así, tanto los consumos puertas adentro de los hogares como los que ocurren en el espacio público permiten una conceptualización de los flujos de los habitantes y viajantes al tiempo que informan sobre ciertos ritmos, necesidades e imaginarios que constituyen la vida metropolitana y la formación continua de sus bordes.

Una parte muy importante de la vida en situación de pobreza tiene que ver con el hecho de que se debe aprender a lidiar cotidianamente con la lógica de la restricción. Como con otros campos de las experiencias vitales (v.g el acceso a los servicios educativos y de salud), lo que se compra en el mercado, se troca o se recibe en el marco de programas sociales está marcado por razonamientos evaluativos en donde lo obtenido se juzga a la luz de lo deseado y lo considerado bueno. 
Las familias gestionan a diario un conjunto de recursos que no las conforman y que se perciben como estructuralmente escasos. En el grueso de las entrevistas, puede apreciarse que los actores sociales identifican, por ejemplo, una dieta óptima o buena (la que incluye frutas, productos lácteos y carne de buenos cortes) y una dieta posible. También es frecuente apreciar que desean ofrecer a sus hijos ropa y calzado de buena calidad y alternativas de distracción mercantilizadas -consideradas buenas o mejoresa las que no pueden acceder por carecer de dinero. En el roce cotidiano entre ambas lógicas (la de lo bueno o deseado y la de lo posible) los actores reflexionan y evalúan sobre la restricción y sus efectos. Una vez más y de forma tenue, estos razonamientos permiten acceder a la experiencia de la desigualdad. Por ello, a pesar de haber sido muy transitado, se hace necesario recuperar la cuestión del consumo como espacio de identidad y de distinción en la sociedad capitalista. Como sostiene García Canclini (1999) el consumo ordena, iguala y distingue; otorga y quita pertenencia a un orden cultural y moral.

Por último, el consumo permite apreciar una subjetividad fuertemente marcada por el capital espacial donde no sólo las metas de desplazamiento para el trabajo y las posibilidades de interacción con otros "distintos" parece licuarse cada vez más, sino que el esparcimiento y la sociabilidad se han insularizado también. Así, al tiempo que para los vecinos la feria cartonera se impone frente a los espacios oficiales de consumo y sus pretensiones de integración ciudadana, por su proximidad y sus costos, la sociedad en su conjunto experimenta un proceso de solidificación de las diferencias espaciales, sociales y culturales y contornea un paisaje urbano de creciente fragmentación. 


\section{Q Bibliografía}

"Alabarces, P. y Rodriguez, M. (comps.) (2008). Resistencias y mediaciones. Estudios sobre cultura popular. Buenos Aires: Paidós.

" Aguirre, P (2005). Estrategias de consumo. Qué comen los argentinos que comen, Buenos Aires, Miño y Dávila-CIEPP.

» Appadurai, A. (1991). Introducción: las mercancías y la política del valor. En: Appadurai, Arjun (ed.), La vida social de las cosas, México: Grijalbo.

»Apaolaza, A., Blanco, J., Lerena, N.,López-Morales, E., Lukas, M., y Rivera, M. (2016). Transporte, desigualdad social y capital espacial: análisis comparativo entre Buenos Aires y Santiago de Chile. Íconos. Revista de Ciencias Sociales. 56, Quito, 19-41

»Bertaux, D., (1996). Historias de casos de familias como método para la investigación de la pobreza, Taller. Revista de Sociedad, Cultura y Política, Vol. 1 № 1. Asociación de Estudios en Cultura y Sociedad.

» Bourdieu P. (1988). La Distinción. Madrid, Taurus.

»Cravino, M.C, Fournier, M., Neufeld, M.R y Soldano, D. (2001). Sociabilidad y micropolítica en un barrio 'bajo planes'. En: L. Andrenacci (org.), Cuestión social y política social en el Gran Buenos, Buenos Aires, Ediciones UNGS-AI Margen.

»Crossta, P. (2000). Societá e territorio, al plurale. Lo spazio publico-quale ene pubblico- come esito enetuales dellínterazione sociale. Revista Foedus (Venecia) № 1.

»Chavez Molina, E., Comas, G. y Alonso, J.P. (2009). Ferias urbanas: las lógicas de reproducción entre la "opción y la necesidad". El caso de la feria de San Francisco Solano. Mimeo.

»Da Representação, N. y D. Soldano (2009). Espacios comunes, sociabilidad y Estado. Aportes para pensar los procesos culturales metropolitanos. Apuntes de investigación, 16/17.

" Da Representação, N. y H. Vanoli (2012). Política, ocio y abastecimiento en el Mercado Concentrador de José C. Paz. Una mirada a los consumos y a la oferta en un shopping híbrido. Ponencia presentada en las VII Jornadas de Sociología de la UNGS, ICI-UNGS.

» Fournier, Jean-Marc. (2008). Des mobilités sociales et spatiales au capital spatial. L'exemple de l'élite argentine de Punta del Este en Uruguay, maître de conférences à l'université de Caen, UMR 6590 “Espaces et Sociétés” Le 8 juillet 2008. Recuperado de http://eso.cnrs.fr/spip.php?article311.

»Del cueto, C. y Luzzi, M. (2016). Salir a comprar El consumo y la estructura social en la Argentina reciente. En: Kessler, G. (dir.) La sociedad argentina hoy. Radiografía de una nueva estructura, Buenos Aires: Siglo XXI EditoresFundación OSDE.

"García Canclini, M. (1999). "El consumo cultural: una propuesta teórica". En Guillermo Sunkel (coord.), El consumo cultural en América latina. Bogotá, Convenio Andrés Bello.

» García Canclini, G., Castellanos, A., Mantecón, A. (2011). La ciudad de los viajeros. Travesías e imaginarios urbanos: México 1940-2000. México: FCE. 
» Grignon, C. y Passeron, J-C. (1991). Lo culto y lo popular. Miserabilismo y populismo en sociología y literatura. Buenos Aires: Nueva Visión.

» Guedes, P. y Olivera, N. (2006). La democratización del consumo. En Braudel Papers (Sao Paulo) No. 5.

» Hoggart, R. (1990). La Cultura Obrera en la sociedad de masas, México, Grijalbo.

» Lévy, J. (2003). Capital spatial. En Jacques Lévy et M. Lussault (eds.), Dictionnaire de la géographie et de l'espace des sociétés. Paris: Belin.

»Lussault, M. y Lévy, J. (2003). Dictionnaire de la Géographie et de l'espace des societés. Paris, Belin.

" Marcus, L. (2010). Spatial Capital and how to measure it - an outline of an analytical theory of urban form. The Journal of Space Syntax, Vol 1, No. 1.

» Martín Barbero, J. (1987). De los medios a las mediaciones. Comunicación, cultura y hegemonía. Barcelona, Gustavo Gili.

"Palma Arce, C. (2012). Movilidad y acceso al trabajo. Tesis de Maestría en Metodología de la Investigación Social. UNTREF-Boloña.

»Palma Arce, C. y Soldano, D. (2010). Capital espacial y movilidad cotidiana en la Región Metropolitana de Buenos Aires. Una propuesta analítica y empírica. En Adriana Rofman (comp.), Sociedad y territorio en el conurbano bonaerense. Un estudio de las condiciones socioeconómicas y sociopolíticas de cuatro partidos: San Miguel, José C. Paz, Moreno y Morón. Los Polvorines: Universidad Nacional de General Sarmiento.

"Sarlo, B. (2009). La ciudad vista. Mercancías y cultura urbana. Buenos Aires, Siglo XXI.

"Simmel, G. (1977). Filosofía del dinero. Madrid, Instituto de Estudios Políticos.

"Soldano, D. (2008). Vivir en territorios desmembrados. Un estudio sobre la fragmentación socio-espacial y las políticas sociales en el Área Metropolitana de Buenos Aires (1990-2005)". En Alicia Ziccardi, (comp.) Procesos de urbanización de la pobreza y nuevas formas de exclusión social. Los retos de las políticas sociales de las ciudades latinoamericanas del siglo XXI. Bogotá: Siglo del Hombre Editores, Clacso-Crop

»Soldano, D. (2013). Confinamientos, movilidad e intercambios. Una investigación sobre las condiciones y los modos de vida en la periferia del Gran Buenos Aires. En María Carman, Neiva Vieira da Cunha y Ramiro Segura (Coord.) Segregacióny diferencia en la ciudad. Quito, FLACSO, Sede Ecuador: Consejo Latinoamericano de Ciencias Sociales (CLACSO): Ministerio de Desarrollo Urbano y Vivienda.

»Soldano, D (2018). Experiencias del bienestar. Para una comprensión de la política social desde el sentido común. Ciudadanías. Revista de Políticas Sociales Urbanas 3. Segundo semestre 2018.

"Soldano, D. y Perret Marino, G. (2017). Viajes y experiencias del espacio en los bordes de la ciudad. En D. Soldano (comp), Viajeros del Conurbano Bonaerense. Una investigación sobre las experiencias de la movilidad en la periferia (173-221). Los Polvorines, Argentina: Ediciones UNGS.

» Schutz, A. (1970). Fenomenología del mundo social. Introducción a la sociología comprensiva. Buenos Aires, Paidos.

» Tilly. C (2000). La desigualdad persistente. Buenos Aires, Manantial.

» Thompson, E. P. (1979). La economía moral de la multitud. En: Tradición, 
revuelta y conciencia de clase. Barcelona, Crítica.

»Vanoli, H. y Soldano, D (2011). La feria del nunca jamás. Revista Crisis 3, Buenos Aires

»Wilkis, A. (2015). Sociología moral del dinero en el mundo popular. Estudios Sociológicos XXXIII:9o. Colmex

\section{Daniela Soldano / da.soldano@gmail.com}

Licenciada en Ciencia Política por la Universidad de Buenos Aires (UBA), magíster en Política Social, Facultad Latinoamericana de Ciencias Sociales (FLACSO) y doctora en Ciencias Sociales (UBA). Profesora titular de la Universidad Nacional del Litoral (UNL) e investigadora docente adjunta en el Instituto del Conurbano de la Universidad Nacional de General Sarmiento (ICO/UNGS). 